\title{
Genetic diagnosis of familial hypercholesterolaemia: the importance of functional analysis of potential splice-site mutations
}

M Bourbon, M A Duarte, A C Alves, A M Medeiros, L Marques and A K Soutar

J. Med. Genet. 2009;46;352-357

doi:10.1136/jmg.2007.057000

Updated information and services can be found at:

http://jmg.bmj.com/cgi/content/full/46/5/352

\section{These include:}

Data supplement

"Web only appendices"

http://jmg.bmj.com/cgi/content/full/46/5/352/DC1

References This article cites 28 articles, 14 of which can be accessed free at:

http://jmg.bmj.com/cgi/content/full/46/5/352\#BIBL

$\begin{array}{ll}\text { Rapid responses } & \begin{array}{l}\text { You can respond to this article at: } \\ \text { http://jmg.bmj.com/cgi/eletter-submit/46/5/352 }\end{array}\end{array}$

Email alerting Receive free email alerts when new articles cite this article - sign up in the box at service the top right corner of the article

Notes

To order reprints of this article go to:

http://journals.bmj.com/cgi/reprintform

To subscribe to Journal of Medical Genetics go to:

http://journals.bmj.com/subscriptions/ 


\title{
Genetic diagnosis of familial hypercholesterolaemia: the importance of functional analysis of potential splice-site mutations
}

\author{
M Bourbon, ${ }^{1}$ M A Duarte, ${ }^{1}$ A C Alves, ${ }^{1}$ A M Medeiros, ${ }^{1}$ L Marques, ${ }^{2}$ A K Soutar ${ }^{3}$
}

- Supplementary tables and figures are published online only at http://jmg.bmj.com/content/ vol46/issue5

${ }^{1}$ Unidade de Investigação Cardiovascular, Instituto Nacional de Saúde Dr. Ricardo Jorge, Lisboa, Portugal;

${ }^{2}$ Unidade de I\&D em Imunologia, Instituto Nacional de Saúde Dr Ricardo Jorge, Lisboa Portugal; ${ }^{3}$ MRC-Lipoprotein Group, Clinical Sciences Centre, Hammersmith Hospital, London, UK

Correspondence to: Dr M Bourbon, Unidade de investigacão Cardiovascular, Instituto Nacional de Saúde Dr Ricardo Jorge, 1649-016 Lisboa, Portugal; mafalda.bourbon@ insa.min-saude.pt

Received 18 December 2007 Revised 6 November 2008 Accepted 14 November 2008 Published Online First

7 January 2008

\section{ABSTRACT}

Familial hypercholesterolemia (FH) results from defective low-density lipoprotein receptor (LDLR) activity, mainly due to $L D L R$ gene defects. Of the many different $L D L R$ mutations found in patients with $\mathrm{FH}$, about $6 \%$ of single base substitutions are located near or within introns, and are predicted to result in exon skipping, retention of an intron, or activation of cryptic sites during mRNA splicing. This paper reports on the Portuguese FH Study, which found 10 such mutations, 6 of them novel. For the mutations that have not been described before or those whose effect on function have not been analysed, their effect on splicing was investigated, using reverse transcriptase PCR analysis of $L D L R$ mRNA from freshly isolated blood mononuclear cells. Two of these variants $(c .313+6 \mathrm{~T} \rightarrow \mathrm{C}, \mathrm{c.2389G} \rightarrow \mathrm{T}(\mathrm{p} . \mathrm{V} 776 \mathrm{~L}))$ caused exon skipping, and one caused retention of an intron (c. 1359-5C $\rightarrow G$ ), whereas two others (c.2140+5 G $\rightarrow A$ and c.1061-8T $\rightarrow$ C) had no apparent effect. Any effect of c.1185G $\rightarrow$ C (p.V374V) on splicing could not be determined because it was on an allele with a promoter mutation $(-42 \mathrm{C} \rightarrow \mathrm{G})$ that was probably not transcribed. Variants in four patients lost to follow-up could not be tested experimentally, but they almost certainly affect splicing because they disrupt the invariant $A G$ or $G T$ in acceptor (c.818-2A $\rightarrow$ G) or donor (c.1060+1G $\rightarrow A$, c. $1845+1$ delG and c. $2547+1 \mathrm{G} \rightarrow$ A) spice sites. These findings emphasise that care must be taken before reporting the presence or absence of a splice-site mutation in the $L D L R$ gene for diagnostic purposes. The study also shows that relatively simple, quick and inexpensive RNA assays can evaluate putative splicing mutations that are not always predictable by available software, thereby reducing genetic misdiagnosis of patients with $\mathrm{FH}$.

Familial hypercholesterolemia $(\mathrm{FH})$ is a common autosomal dominant disorder with a frequency of about 1 in 500 in most European populations. Patients diagnosed with FH characteristically have high levels of low-density lipoprotein cholesterol (LDLc) from birth, present with tendon xanthomata, and have an increased risk of premature atherosclerosis and coronary heart disease (CHD). FH results from defective low-density lipoprotein receptor (LDLR) activity, caused mainly by mutations in the LDL receptor gene $(L D L R)$ itself. ${ }^{1}$

Many different types of mutations in $L D L R$ have been found in patients with FH. These range from large deletions and rearrangements that disrupt gene structure to single base substitutions that compromise the structure or function of the protein by introducing a premature termination codon or a single amino acid substitution. However, a significant proportion (approx 6\%) of the single base substitutions observed in patients with FH do not affect the protein coding sequence. These variants are often located in the $5^{\prime}$ splicedonor site or the 3 ' splice-acceptor site of an intron, and are predicted to result in either exon skipping or retention of an intron in the mRNA, although this has not always been confirmed experimentally. Other intronic variants may lie outside the consensus splice-site sequence, but affect the splicing branch point ${ }^{2}$ or create an alternative splice site that is used preferentially. ${ }^{3}$ Alternative splice sites can also arise as a result of a single base substitution in the coding sequence. ${ }^{4}$

Although some splice-site mutations are easily identified, based on a priori knowledge of their location in the gene and their likely effect on the consensus sequences for splice sites, others are more difficult to predict. Consequently, software packages have been developed that provide a "splice score" for a known or potential splice site, based on the consensus sequences for natural splice sites, and thereby indicate whether a particular nucleotide substitution is likely to influence splicing. ${ }^{5-7}$ However, several of the known natural splice sites in the $L D L R$ gene have relatively low scores, so predictions are not always safe, and only analysis of mRNA from the patient's cells can confirm that splicing is affected. To date, this has been performed for only a few splicing alterations, probably because of the perceived need to establish stable cell lines from the patient to allow analysis of $L D L R$ mRNA. ${ }^{3} 48$

This paper reports on the Portuguese FH Study, which was implemented to perform molecular characterisation of patients with a clinical diagnosis of $\mathrm{FH}$ as an aid to diagnosis and identification of index cases and affected relatives. ${ }^{9}$ In total, 10 potential splicing mutations were found, 6 of which had either not been described previously or for which their effect on function had not been analysed. ${ }^{10}$ The aim of this study was to determine whether these variants were mutations that affected splicing of the LDLR mRNA. For this, $L D L R$ mRNA from freshly isolated blood mononuclear cells from patients with FH was analysed by reverse transcriptase (RT)-PCR.

\section{METHODS}

\section{Patient recruitment}

Samples of whole blood $(10 \mathrm{ml}$ for children and $15 \mathrm{ml}$ for adults) were taken from index patients with a potential splice-site mutation in $L D L R$ 
found during the Portuguese FH Study. One of the index patients (patient $6 \mathrm{a}$ ) died as a result of myocardial infarction at the start of the study, so cells were obtained from an affected relative who carried the same variant allele (patient $6 \mathrm{~b}$ ).

\section{RNA extraction and reverse transcriptase (RT) reaction}

The blood samples were collected into ethylene diamine tetraacetic acid (EDTA) tubes, to which an equal volume of Lymphoprep (Axis Shield) was added. The tubes were spun in a centrifuge for $30 \mathrm{~min}$ at $974 \mathrm{~g}$ and a temperature of $4^{\circ} \mathrm{C}$ to isolate mononuclear cells (lymphocytes and monocytes). The ring of mononuclear cells was carefully removed, resuspended in $20 \mathrm{ml}$ of Hanks balanced salt solution (HBSS; Gibco; Invitrogen Corporation), and pelleted by centrifugation for $8 \mathrm{~min}$ at $454 \mathrm{~g}$ and $4^{\circ} \mathrm{C}$. Any remaining erythrocytes were lysed by resuspension of this cell pellet in $10 \mathrm{ml}$ of lysis buffer $(0.01 \mathrm{mmol} / \mathrm{l}$ TrisHCl, $\left.0.15 \mathrm{mmol} / 1 \mathrm{NH}_{4} \mathrm{Cl}, \mathrm{pH} 7.4\right)$, and incubated at $37^{\circ} \mathrm{C}$ for $10-15 \mathrm{~min}$, followed by centrifugation for $8 \mathrm{~min}$ at $1500 \mathrm{rpm}$ and $4^{\circ} \mathrm{C}$. The mononuclear cells were then washed twice with HBSS by centrifugation as above. Total RNA was extracted (RNeasy Mini Kit; Oiagen, Valencia, California, USA), including the optional DNAse I incubation. This procedure yielded $6.5-20 \mu \mathrm{g}$ of total RNA $(200-600 \mathrm{ng} / \mu \mathrm{l})$.

To prepare cDNA, $1 \mu \mathrm{g}$ of RNA was reverse transcribed (Ready-To-Go You-Prime First-Strand Beads Kit; Amersham Biosciences, Amersham, Buckinghamshire, UK).

\section{Reverse transcriptase PCR and analysis of PCR fragments}

Amplification of the cDNA fragments of interest was performed in a T3000 thermocycler (Biometra, GmbH. Niedersachsen, Germany). All the primers were designed using PrimerSelect V.4.05, software, incorporated in the DNAstar software (DNAstar Inc, Madison, Wisconsin, USA) and Primer3 software. In order to amplify large fragments, the Expand Long Template PCR System was also used, according to the supplier's instructions (Roche Applied Science, Madison, Wisconsin, USA). All PCR products were treated with ExoSAP (USB, Cleveland, Ohio, USA, and Amersham Biosciences) and sequenced with the PCR forward and reverse primers (as indicated in figure legends) in an automated sequencer with 16 capillaries (3100 Genetic Analyzer; Applied Biosystems, Foster City, California, USA).

When necessary, common genomic sequence variations and other fragments of the LDLR gene were analysed as described elsewhere. ${ }^{10}$

\section{Splice-site scores and splice-site prediction}

Splice-site scores were calculated with Splice-Site Score Calculation software (http://rulai.cshl.edu/new_alt_exon_db2/ HTML/score.html).

\section{RESULTS}

Blood samples for mRNA analysis were obtained from six index patients, whose clinical characteristics and putative $L D L R$ defects are shown in table 1 . The clinical phenotype of these patients is presented in supplementary table 1 (online). The remaining four patients, with alterations c.818-2A $\rightarrow \mathrm{G}$, c. $1060+1 \mathrm{G} \rightarrow \mathrm{A}$, c. $1845+1 \mathrm{delG}$ and c. $2547+1 \mathrm{G} \rightarrow \mathrm{A}$ were lost to follow-up and fresh blood samples were unobtainable, but the pathogenicity of these variants is not in any doubt.

Our novel approach for the isolation of total RNA from fresh blood cells allowed the set-up of RT-PCR on the same day as blood collection (or on the following day for samples sent by mail). Sufficient RNA could be extracted from fresh blood mononuclear cells to perform at least 100 PCR tests. Fragments of LDLR mRNA were amplified by RT-PCR with appropriate primers spanning regions encoded by different exons in order to detect splicing variants. Fragments of up to $600 \mathrm{bp}$ could be amplified readily.

\section{Mutations that affect mRNA splicing}

c. $313+6 \mathrm{~T} \rightarrow \mathrm{C}$, intron 3

A single base substitution of $\mathrm{T}$ to $\mathrm{C}$ at nucleotide c. $313+6$ at the $5^{\prime}$ end of intron 3 was found in a heterozygous index patient with $\mathrm{FH}$ who also carried a second potentially defective allele, A410T. ${ }^{10}$ Only the $313+6$ variant was found in this patient's hypercholesterolaemic father (fig 1A), suggesting that this was the pathogenic variant in the father, and that it must affect splicing. This was supported by the calculated splice-site scores: 8.1 for the normal splice site and 3.7 for the variant site. When a fragment of LDLR mRNA encompassing the region encoded by exons 1 to 4 was amplified from the patient's cells by RT-PCR, the agarose gel electrophoresis showed the amplification of two fragments of $441 \mathrm{bp}$ (normal size product) and $318 \mathrm{bp}$ (supplementary fig 1B online). The nucleotide sequence of the total PCR product revealed a double sequence after the nucleotides encoded by exon 2, showing both the expected sequence and a sequence in which exon 2 was followed by exon 4 (supplementary fig 1C online), indicating the skipping of exon 3 in the mRNA from one allele (fig 1B). This alteration was not present in a panel of 75 normolipidaemic Portuguese controls.

\section{$\mathrm{c.} 2389 \mathrm{G} \rightarrow \mathrm{T}(\mathrm{p} . \mathrm{V} 776 \mathrm{~L})$ exon 16}

A single base substitution of $\mathrm{G} \rightarrow \mathrm{T}$ at nucleotide 2389 , the last nucleotide of exon 16, was found in a heterozygous index patient with $\mathrm{FH}$ and relatives with hypercholesterolaemia (III:2 and III:3, fig 2A). From the coding sequence, this variation is predicted to result in a conservative amino acid substitution (V776L) that would be unlikely to affect LDLR function, but the nucleotide also lies in the splice site at the end of exon 16. Calculation of the splice site scores showed a reduction from 7.1 for the natural site to 3.6 for the variant site, indicating that this alteration might affect splicing. When a fragment of mRNA encompassing the region encoding exons 15-18 was amplified from the index patient's cells, agarose gel electrophoresis of the product revealed two fragments, the expected fragment of $490 \mathrm{bp}$ and a smaller fragment of approximately $412 \mathrm{bp}$ (supplementary fig 2B online). Nucleotide sequencing showed that the $412 \mathrm{bp}$ fragment corresponded to a fragment lacking exon 16 and that fragment $490 \mathrm{bp}$ corresponded to the expected fragment (supplementary fig 2C) as demonstrated in fig $2 \mathrm{~B}$ This alteration was not present in a panel of 75 normolipidaemic Portuguese controls.

\section{c. $1359-5 \mathrm{C} \rightarrow \mathrm{G}$, intron 9}

A single base substitution of $C \rightarrow G$ at nucleotide $1359-5$ at the $3^{\prime}$ end of intron 9 was found in one index patient and other family members with hypercholesterolaemia (II:2 and III:1, fig $3 \mathrm{~A}$ ). However, the variant was not present in a further family member (III:3) who also had hypercholesterolaemia, and thus this variant gene did not show full co-segregation with the disorder (fig 3A). Nonetheless, the nucleotide substitution reduced the calculated splice-site score from 6.8 to 4.3. In order to detect any effect of this mutation on splicing, a fragment of LDLR mRNA encompassing the region encoded by exons 8-10 was amplified by RT-PCR from the patient's cells. Agarose gel 
Table 1 Characterisation of patients in the study

\begin{tabular}{|c|c|c|c|c|c|c|}
\hline \multicolumn{3}{|c|}{ Patient } & \multirow[b]{2}{*}{ Gender } & \multicolumn{2}{|l|}{ LDLR gene variant } & \multirow[b]{2}{*}{ Reference } \\
\hline No & Type & $\begin{array}{l}\text { Age, } \\
\text { years* }\end{array}$ & & Base substitution & Location & \\
\hline \multirow[t]{2}{*}{1} & Index & $41-44$ & $\mathrm{~F}$ & $313+6 \mathrm{~T} \rightarrow \mathrm{C}$ & Intron 3 & Novel \\
\hline & & & & c. $1291 \mathrm{G} \rightarrow \mathrm{A}(\mathrm{p} . \mathrm{A} 410 \mathrm{~T})$ & Exon 9 & 10 \\
\hline 2 & Index & $33-36$ & M & $\mathrm{c.2389G} \rightarrow \mathrm{T}(\mathrm{p} . \mathrm{V} 776 \mathrm{~L})$ & Exon 16 & 11 \\
\hline 3 & Index & $73-76$ & $\mathrm{~F}$ & c. $1359-5 \mathrm{C} \rightarrow \mathrm{G}$ & Intron 9 & Novel \\
\hline \multirow[t]{2}{*}{4} & Index & $13-16$ & M & {$[c .1061-8 \mathrm{~T} \rightarrow \mathrm{C}]$ and } & Intron 7 & $11-15$ \\
\hline & & & & {$[c .2177 \mathrm{C} \rightarrow \mathrm{T}(\mathrm{p} . \mathrm{T705I})]$} & Exon 15 & 1617 \\
\hline 5 & Index & $61-64$ & $\mathrm{~F}$ & c. $2140+5 G \rightarrow A$ & Intron 14 & $11 \quad 13 \quad 18-20$ \\
\hline \multirow[t]{2}{*}{$6 a \dagger$} & Index & $45-48$ & M & $c .1185 G \rightarrow C(p . V 374 V)$ & Exon 8 & Novel \\
\hline & & & & c. $-42 \mathrm{C} \rightarrow \mathrm{G}$ & Promotor & 2122 \\
\hline \multirow[t]{2}{*}{$6 b$} & Relative of $6 a$ & $5-8$ & $\mathrm{~F}$ & $c .1185 G \rightarrow C(p . V 374 V)$ & Exon 8 & Novel \\
\hline & & & & c. $-42 \mathrm{C} \rightarrow \mathrm{G}$ & Promotor & 2122 \\
\hline
\end{tabular}

*During study; †died 2007.

electrophoresis revealed two fragments in the amplification reaction: the expected fragment of $325 \mathrm{bp}$, plus a larger fragment of approximately $410 \mathrm{bp}$ (supplementary fig 3B). The nucleotide sequence of the total PCR product revealed a double sequence (supplementary fig 3C), with both the expected sequence and a sequence in which the nucleotide sequence of exon 9 was followed by the sequence of intron 9 , showing that intron 9 was retained in the $410 \mathrm{bp}$ fragment (fig 3B). This alteration was not present in a panel of 75 normolipidaemic Portuguese controls.

\section{Potential or reported splicing variants that do not affect splicing}

\section{c. $1061-8 \mathrm{~T} \rightarrow \mathrm{C}$, intron 7}

A single base substitution of $\mathrm{T} \rightarrow \mathrm{C}$ at nucleotide $1061-8$ at the $3^{\prime}$ end of intron 7 was found in one index patient and several other family members with hypercholesterolaemia (II:1-4, II6, and III:3; fig 4A). However, the variant was not present in a further family member (I:2) with hypercholesterolaemia (fig 4A), and the splice-site scores did not show any significant difference (11.7 vs 11.8). This indicated that the alteration was unlikely to affect splicing, and this was confirmed when mRNA
A

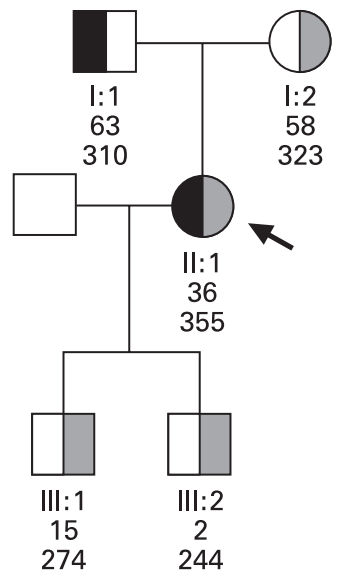

B

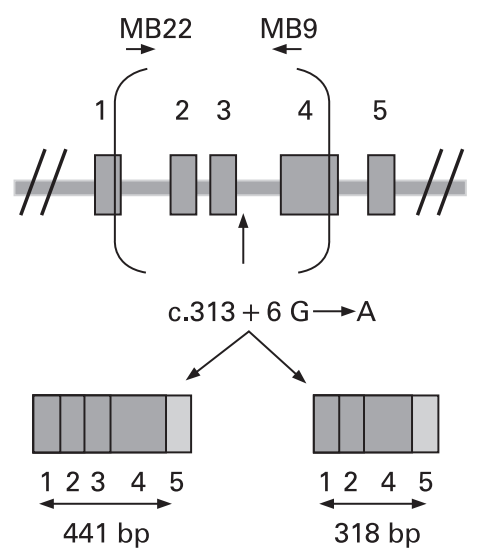

Figure 1 Effect of the $c 313+6 T \rightarrow C$ mutation on LDLR mRNA. (A) Pedigree of index patient 1 (indicated by arrow); half-filled black symbols, heterozygous for $313+6 \mathrm{~T} \rightarrow \mathrm{C}$; half-filled light grey symbols, heterozygous for A410T. Below each symbol are generation numbers followed by age and pre-treatment cholesterol levels (mg/dl). (B) Diagram showing the location of primers used and the two fragments obtained. from the patient's cells was analysed. Amplification of a fragment of LDLR mRNA encompassing the region encoded by exons 6-9 produced a single product of the expected size (supplementary fig 4B). A panel of 75 normolipidaemic Portuguese controls was also screened for this alteration and it was found in 2 of them.

\section{c. $2140+5 \mathrm{G} \rightarrow \mathrm{A}$ intron 14}

A single base substitution of $\mathrm{G}$ for $\mathrm{A}$ at nucleotide 2140 at the $5^{\prime}$ end of intron 14 was found in one index patient and in a family member with hypercholesterolaemia (II:1, fig 5A). This variant had been reported before as the cause of $\mathrm{FH}$, but this was later refuted when the variant was found to occur in normolipidaemic people. ${ }^{20}$ Because the splice-score software showed a reduction from 8.1 for the natural site to 4.7 for the variant, we investigated whether this variant might have an effect on RNA processing in our index patient's cells. When a fragment of LDLR mRNA encompassing a region encoded by exons 13-15 was amplified by RT-PCR from the patient's cells, only the expected fragment of $359 \mathrm{bp}$ was present, (supplementary fig $5 \mathrm{~B}$ online), confirming that this variant has no effect on splicing. A panel of 75 normolipidaemic Portuguese controls was screened for this alteration and it was found in 1 of them.
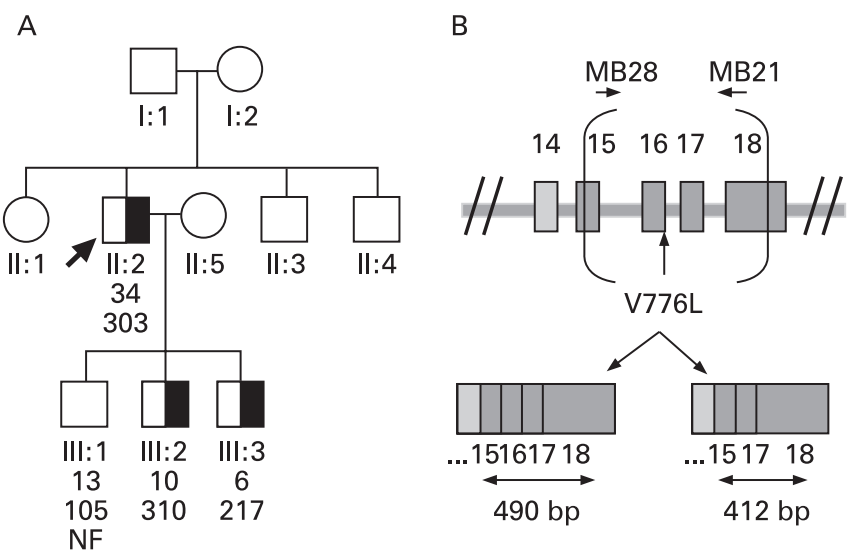

Figure 2 Effect of the $c .2389 \mathrm{G} \rightarrow \mathrm{T}$ (p.V776L) mutation on LDLR mRNA. (A) Pedigree of index patient 2 (indicated by arrow). Half-filled black symbols, heterozygous for the V776L mutation. Below each symbol are generation numbers followed by age and pre-treatment cholesterol levels in $\mathrm{mg} / \mathrm{dl}$. NF, mutation not found. (B) Location of primers used and the representation of the two fragments obtained. 
A

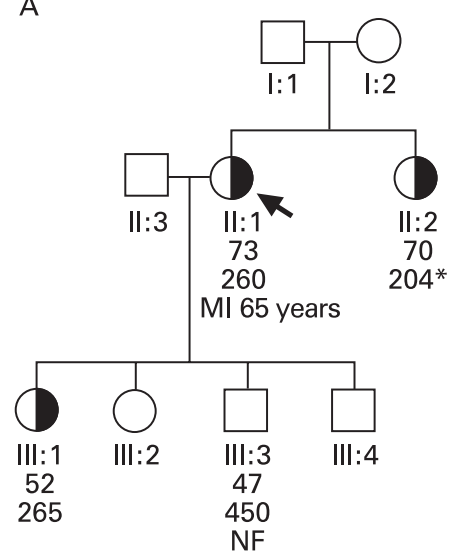

B

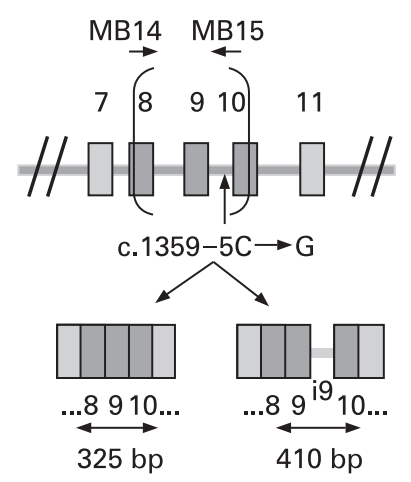

Figure 3 Effect of the $c .1359-5 \mathrm{C} \rightarrow \mathrm{G}$ mutation on LDLR mRNA. (A) Pedigree of index patient 3 (indicated by arrow). Half-filled black symbols, heterozygous for c.1359-5C $\rightarrow$ G. Below each symbol are generation numbers followed by age and pre-treatment cholesterol levels in $\mathrm{mg} / \mathrm{dl}$ (except when marked with ${ }^{*}$ ); $\mathrm{Ml}$, myocardial infarction; $\mathrm{NF}$, mutation not found. (B) Location of primers used and the two fragments obtained.

\section{Use of a potential splicing variant $(c .1185 G \rightarrow C(p . V 374 V))$ in exon 8 to characterise a promoter mutation}

A single base substitution $G$ to $C$ at nucleotide 1185 at the second nucleotide of the last codon of exon 8 was found in a heterozygous index patient with $\mathrm{FH}$ and other relatives with hypercholesterolaemia (II:1 and III:2, fig 6A). There was no difference between the calculated splice-site scores for the normal and variant alleles (6.8 vs 6.8), but as it cosegregated with hypercholesterolaemia in this family and no other variant was identified, it was decided to investigate whether any abnormal splicing could be detected. Fresh blood cells from II:1 and III:2, both heterozygous for the variant, were available, as well as cells from another relative (III:1) who did not carry this variant allele (fig 6A). A fragment encompassing a region encoded by exons 6-9 was amplified from mRNA from these cells, and agarose gel electrophoresis showed that only the expected product of $319 \mathrm{bp}$ was obtained for all three family members (supplementary fig 6B online).

To exclude the possibility that retention of intron $8 \mathrm{had}$ resulted in an abnormal mRNA that could not be amplified by standard RT-PCR, long-range PCR was performed using the forward primer in exon 6 and a reverse primer in intron 8, with the patient's cDNA and genomic DNA as templates. Because this amplified the correct fragment of about $4.3 \mathrm{~kb}$ from genomic DNA, and no amplification was seen when mRNA

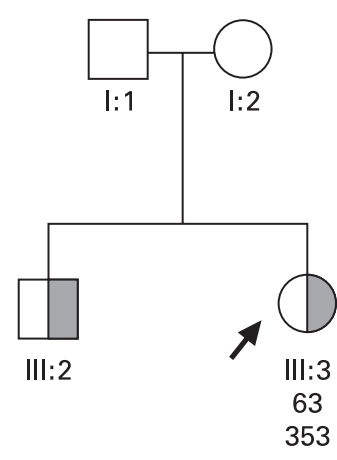

Figure 5 Lack of effect of the c. $2140+5 \mathrm{G} \rightarrow \mathrm{A}$ alteration on mRNA splicing. (A) Pedigree of index patient 5 (indicated by arrow). Half-filled black and grey symbols, heterozygous for c. $1061-8 \mathrm{~T} \rightarrow$ C. Below each symbol are generation numbers followed by age and pre-treatment cholesterol levels in $\mathrm{mg} / \mathrm{dl}$.

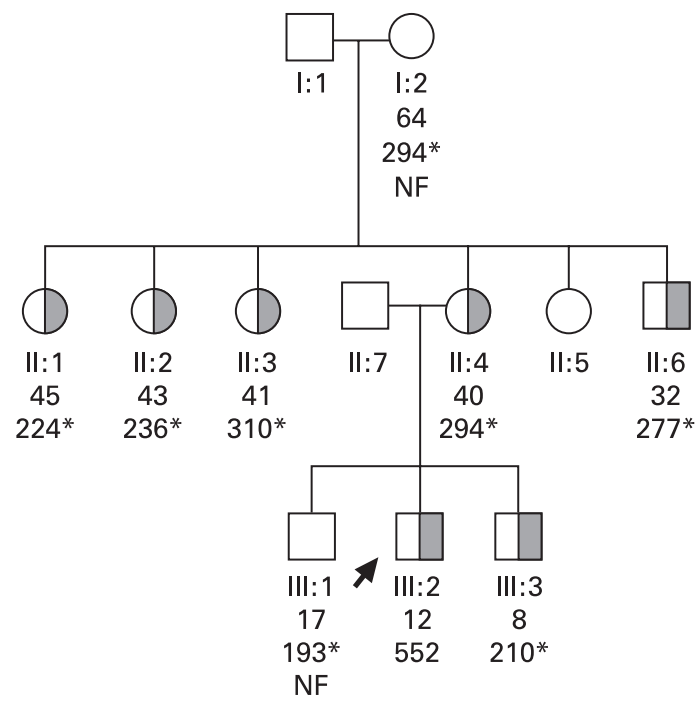

Figure 4 Lack of effect of the c.1061 $-8 \mathrm{~T} \rightarrow \mathrm{C}$ variant on LDLR mRNA splicing. (A) Pedigree of index patient 4 (indicated by arrow). Half-filled black and grey symbols, heterozygous fr c.1061-8T $\rightarrow$ C. Below each symbol are generation numbers followed by age and pre-treatment cholesterol levels (mg/dl) (except when marked with ${ }^{*}$ ). NF, variant not found.

was used as template, it was clear that this alteration did not lead to the retention of intron 8 in the mRNA (supplementary fig 6C online).

However, analysis of the nucleotide sequences of the amplified fragments from both affected relatives revealed that the mRNA was apparently homozygous for the common $G$ at position 1185 (fig 6B), indicating that the rare allele carrying the $1185 \mathrm{C}$ was not detectable in mRNA. This was confirmed by analysis of other polymorphic sites in genomic DNA and mRNA. Individual II:1 was heterozygous for several common polymorphisms in the LDLR coding region, and analysis of mRNA from her cells revealed that the mRNA was apparently homozygous at all these sites, confirming that only one allele was expressed as mRNA (supplementary fig 6E online). III:2 was homozygous in genomic DNA at all sites tested and thus further analysis of her mRNA provided no additional information.

As there was no evidence for a mutation giving rise to a premature termination codon that might lead to rapid decay of the mRNA, it appeared that either only one allele was transcribed in carriers of the V374V allele, or that there was a mutation in the non-coding region on this allele that destabilised the mRNA. To investigate this, the promoter region of the LDLR was re-analysed in genomic DNA from these affected subjects. A single nucleotide substitution of $C$ to $G$ at position -42 , which lies in a critical SRE sequence ${ }^{212}$ was found in all the family members with the V374V alteration and not in the one normolipaemic relative who did not carry this alteration (fig 6A). The cosegregation pattern indicated that both alterations are on the same allele. These results indicated that the allele carrying the V374V variant is apparently not transcribed in the cells due to the promoter mutation. The alteration V374V was not found in a panel of 75 normolipidaemic Portuguese controls.

\section{DISCUSSION}

Confirming whether any genetic alteration is the underlying cause of the disease in an individual is important to establish the 
Figure 6 Analysis of LDLR mRNA in cells from carriers of $\mathrm{c} .1185 \mathrm{G} \rightarrow \mathrm{C}$ (V374V) and $-42 \mathrm{G} \rightarrow \mathrm{C}$. A) Pedigree of index patient 6 (indicated by arrow). Halffilled black symbols, heterozygous for the c. $1185 \mathrm{G} \rightarrow \mathrm{C}$ and $-42 \mathrm{G} \rightarrow \mathrm{C}$; crossed symbol, index patient is deceased. Below each symbol are generation numbers followed by age and pre-treatment cholesterol levels (mg/dl). Ml, myocardial infarction; NF, where the family mutation was not found. (B) Nucleotide sequences of a fragment containing exon 8 and intron 8 amplified from genomic DNA, showing heterozygosity for $\mathrm{C.} 1185 \mathrm{G} \rightarrow \mathrm{C}$ in both relatives $\mathrm{II} 1$ and III:2, and of a fragment of LDLR mRNA encompassing exons 6-9 amplified by RT-PCR from the patient's cells, showing homozygosity for the common allele.
A

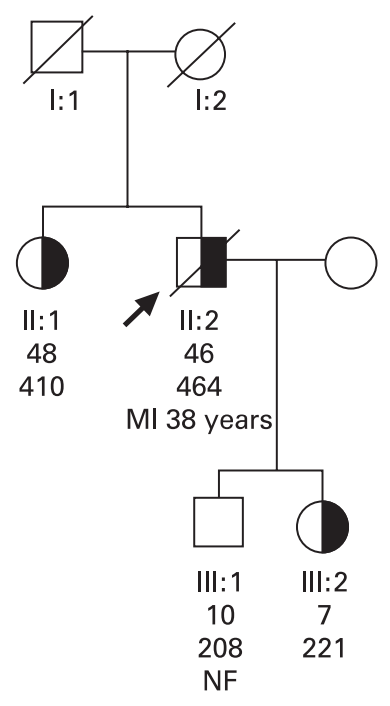

B

Relative II:1

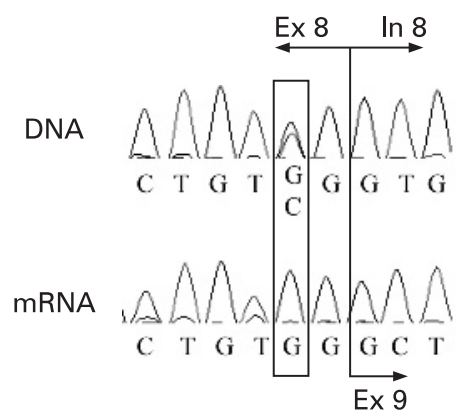

Relative III:2

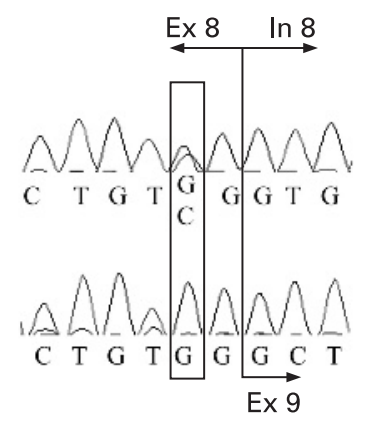

correct diagnosis so that adequate treatment and genetic screening of the family can be implemented. For this, functional assays are necessary for many of the novel alterations found, especially where mRNA splice sites might be involved. The novel method presented here allows the isolation of total RNA from fresh blood cells and the set-up of RT-PCR on the day of the blood collection (or on the following day for samples sent by mail), saving weeks of the extensive cell culture necessary to obtain stable cell lines. This novel approach uses simple methods that will enable many researchers to investigate putative splice-site mutations rapidly and inexpensively avoiding the publication of false splice-site mutations.

Our sample of six putative splice-site mutations was successfully analysed by the described methods. Three of the alterations were found to affect splicing and the other three did not. Substitution of c. $313+6 \mathrm{~T} \rightarrow$ C leads to skipping of exon 3 , and this has been shown previously to result in very low levels of LDL receptor activity in cells. ${ }^{8}$ The substitution c. $1359-5 \mathrm{C} \rightarrow \mathrm{G}$ led to retention of intron 9; this is predicted to result in a protein with two additional incorrect amino acid residues after those encoded by exon 9 followed by a termination codon. The alteration c.2389G $\rightarrow \mathrm{T} \quad(\mathrm{p} . \mathrm{V} 776 \mathrm{~L}$ ) results in exon skipping, leading to the in-frame deletion of the 26 codons of exon 16 that encode the membrane-spanning domain important for the anchoring of the receptor to the cell membrane. Thus these three alterations can clearly be considered as disease-causing mutations. None of the 75 people from a control group of the Portuguese normolipidaemic population had these alterations.

Two of the variants tested did not affect splicing. One of these, c.1061-8T $\rightarrow$ C, did not cosegregate with hypercholesterolaemia in the family, thus raising doubts about its pathogenicity, and furthermore, it was located in the last nucleotide of the consensus splice-site sequence, considered to be relatively unimportant for correct splicing. As described previously, ${ }^{11-15}$ the c.1061-8T $\rightarrow \mathrm{C}$ splice-site alteration is most likely a paucimorphism in complete linkage disequilibrium with the T705I mutation, and indeed this same alteration, now considered to be non-pathogenic, ${ }^{16}{ }^{17}$ was also present in our index patient. As described previously, ${ }^{15}$ this modification in the polypyrimidine tract of the splice-acceptor site for intron 7 is not predicted to have a significant effect on splicing, as was shown in our study. In our population this alteration seems to be a polymorphism. as it was found in 2 of 75 normolipidaemic Portuguese controls.

The second alteration that had no effect on splicing, c. $2140+5$ $\mathrm{G} \rightarrow \mathrm{A}$, has been described previously as the cause of disease in other patients with $\mathrm{FH}$, but has also been reported to occur in normolipidaemic subjects, ${ }^{20}$ thus our result was not surprising. In addition, the analysis of 75 Portuguese normolipidaemic controls revealed that 1 had this common alteration, indicating that this is a polymorphism as it is present in $>1 \%$ of a normal population. It is worth noting that the SSSC software predicted a marked decrease in the splice-site score for this variant allele, and therefore failed to predict the correct effect of this alteration on mRNA splicing. Another commonly used algorithm for the prediction of splice mutations $(\mathrm{SSPNN})^{23}$ gave similar results, although the numerical values were different (supplementary table 2 online), and if anything, the score for the variant was relatively lower according to SSPNN. This indicates that software can only be used to suggest possible splice variants, and that functional characterisation is always necessary for confirmation. Although no variant products were detected, and this variant occurs in normolipidaemic people, it is possible that splicing is less efficient for this allele, which could be determined by quantitative RT-PCR. However, little is known about whether both alleles are expressed equally in normolipidaemic individuals, so this question is outside the scope of this paper but is currently under investigation.

Some reports describe distinct splicing patterns in different cell types, and some variant splicing has been found for exons 4 and 12 of the LDL receptor gene in normolipidaemic people. ${ }^{24}{ }^{25}$ In our study, we compared LDLR mRNA splicing in the same cells (fresh lymphocytes) from normolipidaemic and hypercholesterolaemic individuals, suggesting that the different splicing patterns we found are most probably the cause of their disease. None of our mutations involved exons 4 or 12 . Ideally, LDL receptor mRNA splicing should be assessed in the patient's hepatocytes, but this is clearly not feasible.

Any effect of the V374V alteration on splicing could not be assessed, as it was located on an allele that also has a mutation at position -42 in the proximal promoter of $L D L R$. This mutation apparently lead to the non-production of mRNA, as determined from a comparison of common sequence variations 
in mRNA and DNA from one of the affected patients who was heterozygous at several sites in the genomic DNA, as well as from the absence of the V374 variant in mRNA from all carriers. This promoter mutation has been described previously ${ }^{21} 22$ but no cell studies had been carried out to confirm its effect. Other promoter mutations in the same SRE (eg, at -43 and $-49^{26}{ }^{27}$ ) have been reported to reduce mRNA expression.

There is little doubt about their pathogenicity of the remaining putative splice-site alterations that were not studied here at the mRNA level $($ c. $818-2 A \rightarrow G, \quad$ c.1060+1G $\rightarrow A$, c. $1845+1$ delG and c. $2547+1 \mathrm{G} \rightarrow \mathrm{A})$. Three of these affect the $\mathrm{G}$ in the GT at the $5^{\prime}$ end of an intron, the most conserved region for splicing. A mutation in this location (c.313+1 $\mathrm{G} \rightarrow \mathrm{A}$ that has previously been shown to affect splicing ${ }^{8}$ was also found in the Portuguese FH study. ${ }^{9}$ The fourth variant changes the invariant AG in the acceptor splice site for intron 8 to GG, and similar mutations at the equivalent site in other introns of the LDLR have been confirmed to result in mis-splicing. ${ }^{26} 28$

Even though all the patients analysed in this study presented with a clinical diagnosis of possible $\mathrm{FH}^{9}$ with very high levels of total cholesterol $(>290 \mathrm{mg} / \mathrm{dl})$, not all the rare putative splice variants found in these patients are the cause of their disease, and other causes must now be sought. It is possible that patients with no functional mutation in $L D L R$ have other variants more distant from intron:exon junctions that affect splicing by influencing cis elements, such as splicing enhancers, exonic and intronic splicing enhancers or splicing silencers, and exonic and intronic splicing silencers, which usually interact with splicing stimulator or inhibitor factors..$^{29-31}$ None of these has yet been described in the LDL receptor gene.

Our findings emphasise the care that must be taken before reporting the presence or absence of a splice-site mutation in the $L D L R$ gene for diagnostic purposes. Our study also encourages the implementation of RNA studies to evaluate putative splicing mutations, which in some cases, are not predicted by the available software and could lead to patients being misdiagnosed on a genetic basis.

\section{REFERENCES}

Acknowledgements: The authors would like to thank the clinicians, Dr A Guerra, Dr I Azevedo, Dr I Gaspar and Dr 0 Rato, for sending the blood samples for this study as well as all patients for collaborating.

Funding: ACA is supported by a research assistant grant: INSA BIC 04/2003-II.

Competing interests: None.

Patient consent: Obtained.

\section{REFERENCES}

1. Goldstein JL, Hobbs HH, Brown MS. The metabolic and molecular bases of inherited disease, 8th edn. New York: McGraw Hill, 2001;1:1981-2030.

2. Webb JC, Patel DD, Shoulders CC, Knight BL, Soutar AK. Genetic variation at a splicing branch point in intron 9 of the low density lipoprotein (LDL)-receptor gene: a rare mutation that disrupts mRNA splicing in a patient with familial hypercholesterolaemia and a common polymorphism. Hum Mol Genet 1996;5:1325-31

3. Graham CA, Mcllhatton BP, Kirk CW, Beattie ED, Lyttle K, Hart P, Neely RD, Young IS, Nicholls DP. Genetic screening protocol for familial hypercholesterolemia which includes splicing defects gives an improved mutation detection rate. Atherosclerosis 2005; 182:331-40.

4. Bourbon $\mathbf{M}$, Sun $\mathbf{X M}$, Soutar AK. A rare polymorphism in the low density lipoprotein (LDL) gene that affects mRNA splicing. Atherosclerosis 2007;195:e17-20.

5. Shapiro MB, Senapathy P. RNA splice junctions of different classes of eukaryotes: sequence statistics and functional implications in gene expression. Nucleic Acids Res 1987; 15:7155-74.
6. Florea L, Di Francesco V, Miller J, Turner R, Yao A, Harris M, Walenz B, Mobarry C, Merkulov GV, Charlab R, Dew I, Deng Z, Istrail S, Li P, Sutton G. Gene and alternative splicing annotation with AIR. Genome Res 2005;15:54-66.

7. Churbanov A, Rogozin IB, Deogun JS, Ali H. Method of predicting splice sites based on signal interactions. Biol Direct 2006;1:10.

8. Sun XM, Patel DD, Bhatnagar D, Knight BL, Soutar AK. Characterization of a splicesite mutation in the gene for the LDL receptor associated with an unpredictably severe clinical phenotype in English patients with heterozygous FH. Arterioscler Thromb Vasc Biol 1995;15:219-27.

9. Bourbon M, Rato 0. Portuguese Familial Hypercholesterolemia Study: presentation of the study and preliminary results. Rev Port Cardiol 2006;25:999-1013.

10. Bourbon M, Alves AC, Medeiros AM, Silva S, Soutar AK. Atherosclerosis 2007:196:633-42.

11. Lombardi MP, Redeker EJ, Defesche JC, Kamerling SW, Trip MD, Mannens MM Havekes LM, Kastelein JJ. Molecular genetic testing for familial hypercholesterolemia: spectrum of LDL receptor gene mutations in The Netherlands. Clin Genet 2000;57:116-24.

12. Jensen HK, Jensen LG, Hansen PS, Faergeman O, Gregersen N. High sensitivity of the single-strand conformation polymorphism method for detecting sequence variations in the low-density lipoprotein receptor gene validated by DNA sequencing. Clin Chem 1996:42:1140-6.

13. Mozas P, Cenarro A, Civeira F, Castillo S, Ros E, Pocovi M. Mutation analysis in 36 unrelated Spanish subjects with familial hypercholesterolemia: identification of 3 novel mutations in the LDL receptor gene. Hum Mutat 2000;15:483-4.

14. Wang J, Ban MR, Hegele RA. Multiplex ligation-dependent probe amplification of LDLR enhances molecular diagnosis of familial hypercholesterolemia. J Lipid Res 2005;46:366-72.

15. Alharbi KK, Aldahmesh MA, Spanakis E, Haddad L, Whittall RA, Chen XH, Rassoulian H, Smith MJ, Sillibourne J, Ball NJ, Graham NJ, Briggs PJ, Simpson IA, Phillips DI, Lawlor DA, Ye S, Humphries SE, Cooper C, Smith GD, Ebrahim S, Eccles DM, Day IN. Mutation scanning by meltMADGE: validations using BRCA1 and LDLR, and demonstration of the potential to identify severe, moderate, silent, rare, and paucimorphic mutations in the general population. Genome Res 2005;15:967-77.

16. Lombardi P, Sijbrands EJ, Kamerling S, Leuven JA, Havekes LM. The T705I mutation of the low density lipoprotein receptor gene (FH Paris-9) does not cause familial hypercholesterolemia. Hum Genet 1997;99:106-7.

17. Heath KE, Whittal RA, Miller GJ, Humphries S. 1705 variant in the low denisty lipoprotein receptor gene has no effect on plasma cholesterol levels. J Med Genet 2000;37:713-15.

18. Amsellem $S$, Briffaut $D$, Carrié $A$, Rabès JP, Girardet JP, Fredenrich $A$, Moulin $P$, Krempf M, Reznik Y, Vialettes B, de Gennes JL, Brukert E, Benlian P. Intronic mutations outside of Alu-repeat-rich domains of the LDL receptor gene are a cause of familial hypercholesterolemia. Hum Genet 2002;111:501-10.

19. Dedoussis GV, Skoumas J, Pitsavos C, Choumerianou DM, Genschel J, Schmidt H, Stefanadis C. FH clinical phenotype in Greek patients with LDL-R defective vs. negative mutations. Eur J Clin Invest 2004;34:402-9.

20. Whittall RA, Matheus S, Cranston T, Miller GJ, Humphries SE. The intron 14 $2140+5 G>A$ variant in the low density lipoprotein receptor gene has no effect on plasma cholesterol levels. J Med Genet 2002;39:e57.

21. Hobbs HH, Brown MS, Goldstein JL. Molecular genetics of the LDL receptor gene in familial hypercholesterolemia. Hum Mutat 1992;1:445-66.

22. Mozas P, Castillo S, Tejedor D, Reyes G, Alonso R, Franco M, Saenz P, Fuentes F, Almagro F, Mata P, Pocoví M. Molecular characterization of familial hypercholesterolemia in Spain: identification of 39 novel and 77 recurrent mutations in LDLR. Hum Mutat 2004;24:187.

23. Reese MG, Eeckman FH, Kulp D, Haussler D. Improved splice site detection in Genie J Comput Biol 1997:4:311-23.

24. Tveten K, Ranheim T, Berge KE, Leren TP, Kulseth MA. Analysis of alternatively spliced isoforms of human LDL receptor mRNA. Clin Chim Acta 2006;3:151-7.

25. Zhu H, Tucker HM, Grear KE, Simpson JF, Manning AK, Cupples LA, Estus S. A common polymorphism decreases low-density lipoprotein receptor exon 12 splicing efficiency and associates with increased cholesterol. Hum Mol Genet 2007:16:1765-72.

26. Mozas P, Galetto R, Albajar M, Ros E, Pocovi M, Rodriguez-Rey JC. A mutation $(-49 \mathrm{C}>\mathrm{T})$ in the promoter of the low density lipoprotein receptor gene associated with familial hypercholesterolemia. J Lipid Res 2002;43:13-18.

27. Jensen LG, Jensen HK, Nissen H, Kristiansen K, Faergeman O, Bolund L, Gregersen $\mathrm{N}$. An LDL receptor promoter mutation in a heterozygous $\mathrm{FH}$ patient with dramatically skewed ratio between the two allelic mRNA variants. Hum Mutat 1996;7:82-4.

28. Lombardi P, Hoffer MJ, Top B, de Wit E, Gevers Leuven JA, Frants RR, Havekes LM An acceptor splice site mutation in intron 16 of the low density lipoprotein receptor gene leads to an elongated, internalization defective receptor. Atherosclerosis 1993;104:117-28.

29. Cartegni L, Wang J, Zhu Z, Zhang MQ, Krainer AR. ESEfinder: A web resource to identify exonic splicing enhancers. Nucleic Acids Res 2003;31:3568-71.

30. Fairbrother WG, Yeo GW, Yeh R, Goldstein P, Mawson M, Sharp PA, Burge CB. RESCUE-ESE identifies candidate exonic splicing enhancers in vertebrate exons. Nucleic Acids Res 2004;32:W187-90.

31. Fairbrother WG, Yeh RF, Sharp PA, Burge CB. Predictive identification of exonic splicing enhancers in human genes. Science 2002;297:1007-13. 